\title{
Performance improvement studies for cutting tools with perforated surface in turning of titanium alloy
}

\author{
Rao Charitha ${ }^{1 *}$, Rao Shrikantha ${ }^{1}$ and Herbert Mervin ${ }^{1}$ \\ ${ }^{1}$ Department of Mechanical Engineering, NITK, Surathkal- 575025, India
}

\begin{abstract}
In turning process, the cutting tool is essential for shaping materials. The cutting tools with various perforated surfaces help to increase the cutting tool life. Also, advances in $\mathrm{CNC}$ machining technologies have enhanced the productivity of machining process. One of the best or futuristic approaches in modern manufacturing engineering is the use of FEM Simulation for the metal cutting process. FEM simulation helps in understanding the metal deformation process and also helps in the reduction of experiments. The simulation helps the researchers to predict the major influencing cutting variable values without carrying out any experiment which is time-consuming and expensive. This research presents the simulation study of the performance of micro-hole patterned Polycrystalline Diamond cutting insert in machining Titanium alloy (Ti-6Al-4V). Micro-holes are drilled using Electrical Discharge Wire Drilling machine on the rake face of Polycrystalline Diamond (PCD) cutting inserts. FEM analysis is carried out to evaluate the effect of perforations on the mechanical integrity of insert. The micro-hole patterned insert is modeled in PRO-E modeler and simulated using DEFORM-3D software. The effective stress, strain, and temperature distribution are analyzed and the results are compared with the normal insert.
\end{abstract}

\section{Introduction}

Titanium alloys are categorized as difficult to cut materials due to their low density, chemical reactivity at high temperatures and poor thermal conductivity. These Titanium alloys have various applications in the field of aerospace, commercial, as well as military and medical applications. The excellent strength-to-weight ratio of Titanium alloy provides a decrease of aircraft parts weight and therefore there is a decrease in fuel consumption and emissions. In aircraft engines, Titanium alloy is used in high and low-pressure compressors and also in the components which are subjected to high centrifugal loads such as disks and blades which have reduced the flow diameters and also components which are worked under severe fatigue conditions [1].

The unique characteristics of Titanium alloy result in high cutting temperature and high level of tool vibration at the tool-chip interface. Usually crater wear is common in the material removal process and is difficult to eliminate. Cutting fluids are applied often during metal removal to improve the wear and friction conditions. The purpose of using

\footnotetext{
* Corresponding author: charithamrao@gmail.com
} 
cutting fluid is for cooling and lubrication. Moreover, it is believed that cutting tool inserts with micro-holes or micro-dimples filled with lubricants are more significant in wear and friction fall at the chip-tool interface [2]. These micro-holes or micro-dimples with lubricants reduce the chip-tool contact area and the lubricant may be pushed out of holes due to the thermal expansion at the chip-tool interface, [3]. The cutting tool with different textures such as perpendicular, cross patterned and parallel geometries, which were used in the machining of aluminium alloy with various groove sizes ranging from microscale to nanoscale have been studied. As a result, coefficient of friction and cutting forces were decreased with a perpendicular textured tool when compared with another type of textured tools, [4]. Micro-textured tools with different geometries such as elliptical, parallel and perpendicular were used to machine steel (\#45 grade) using $\mathrm{MoS}_{2}$ solid lubricant. It was noticed that elliptical grooves had better performance than the parallel and perpendicular textures, [5]. Similar kinds of investigations were performed on different materials with different texture patterns by various authors and they finally concluded that for any given machining parameter the textured cutting tools had better results when compared with the normal insert or non-textured cutting tool[6-9].

The machining process is very complex and cost effective due to the strange properties of a material and different textured pattern on the surface of the cutting insert. Finite Element simulations are boon to the manufacturing industries of machining process to its skills in optimizing the production systems. The FEM tools have assisted in cost reduction of change in design of tools which helps in the improvement of product quality by reducing the manufacturing [10].

Numerical models are important in machining process to predict or enhance the machining factors and leads to the reduction of cost in the experimental process. The FEM has predicted the machining output parameters such as stress-strain, cutting temperatures and cutting force components during the machining of Titanium alloy.

The Johnson-Cook (JC) model is used extensively in deformation process due to its flexible nature of data in flow stress is suitable for FEM simulation code. But there is a requirement to estimate the different material models based on the applicability in the context of deforming simulations. The Johnson-Cook material model selected for this analysis is Lesuer (2000) [11].

The thermal and mechanical properties of the tool and workpiece, friction consideration, and fracture conditions are put up in the FEM model. Flow stress data for the model is found out for the range of effective Stress, temperature distribution, and strain. The simulations are being performed based on the machining conditions of Titanium alloy (Ti-6Al-4V). A relative study on the enactment of different designs of Micro-holes on the rake and flank face of the cutting insert is done.

\section{Johnson-Cook Model (JC model)}

The constitutive material model, for FEM analysis, is essential to relate stress, strain, and temperature. To calculate the flow stress for Titanium alloy, the eq. (1) is used to model, and was proposed by Johnson Cook. This constitutive Johnson-Cook model describes the effective strain, stress, and temperature distribution effects. The main disadvantage of using Johnson-Cook model is that the deformations could not be predicted below the room temperature owing to lack of thermal tempering [12].

$$
\sigma=\left[\mathrm{P}+\mathrm{Q} \varepsilon^{\mathrm{n}}\right]\left[1+\mathrm{R} \ln \left(\varepsilon^{\prime} / \varepsilon^{\prime}{ }_{\mathrm{o}}\right)\right]\left[1-\left\{\left(\mathrm{T}-\mathrm{T}_{\text {room }}\right) /\left(\mathrm{T}_{\text {melt }}-\mathrm{T}_{\text {room }}\right)\right\}^{\mathrm{m}}\right]
$$

where, $\mathrm{T}$ is the temperature of work material, $\mathrm{T}_{\text {room }}$ is the room temperature; $\mathrm{T}_{\text {melt }}$ is melting temperature of workpiece, $\varepsilon^{\mathrm{n}}$ is plastic strain, $\varepsilon^{\prime}{ }_{o}$ is reference plastic strain rate, $\varepsilon^{\prime}$ is 
plastic strain rate, $\mathrm{P}$ is yield stress, $\mathrm{Q}$ is modulus of hardening, $\mathrm{R}$ is coefficient of strain rate sensitivity, $m$ is thermal softening coefficient and $n$ is co-efficient of hardening. The strain rate $\varepsilon$ ' is normalized with reference strain rate $\varepsilon^{\prime}$.

The constants [11] were calculated with the help of least square technique which is fitted with an equation of power law. The other parameters are preferred based on the experimentation and the flow stress data to compute for JC material model. Table 1 shows the material properties and JC material model for the research work.

Table 1. JC model constants for Titanium alloy (Ti-6Al-4V) [13]

\begin{tabular}{|l|l|}
\hline Young's modulus & $380 \mathrm{GPa}$ \\
\hline Thermal conductivity & $4.63 \mathrm{~W} / \mathrm{mK}$ \\
\hline Poisson's ratio & 0.23 \\
\hline Heat Capacity & $565 \mathrm{~J} / \mathrm{KgK}$ \\
\hline Thermal Expansion & $6.5 \times 10^{-6}$ \\
\hline Emissivity & 0.07 \\
\hline Yield Strength $(\mathrm{P})$ & $896 \mathrm{MPa}$ \\
\hline Modulus of hardening $(\mathrm{Q})$ & $656 \mathrm{MPa}$ \\
\hline Strain rate sensitivity Coefficient $(\mathrm{R})$ & 0.128 \\
\hline Thermal softening Coefficient $(\mathrm{m})$ & 0.8 \\
\hline Hardening Coefficient $(\mathrm{n})$ & 0.5 \\
\hline Plastic Strain $\left(\varepsilon_{\mathrm{o}}\right)$ & $1 \mathrm{~s}^{-1}$ \\
\hline Melting Temperature of work-piece & 1650 \\
\hline
\end{tabular}

\section{Orthogonal Machining of Titanium alloy}

The orthogonal machining experiments were performed on Maxturn CNC lathe with a billet of Titanium alloy (Ti-6Al-4V) as work-material under dry condition and Minimum Quantity Lubrication (MQL) system. The cutting speeds were 100,125,150,175 and 200 $\mathrm{m} / \mathrm{min}$ with a constant feed rate and depth of cut of $0.05 \mathrm{~mm} / \mathrm{rev}$ and $0.5 \mathrm{~mm}$ [14-15]. An advanced Polycrystalline Diamond (PCD) tool was used as a Cutting insert. The cutting insert was modified with the micro-holes on the rake face of the insert which help in the micro-pool lubrication in the reduction of heat generation at the tool-chip interface. The cutting force is determined based on the power consumption during the cutting operation. The chip morphology based on the chips collected during the experimentation was scrutinized under Scanning Electron Microscope (SEM), which calibrates and captures the chips. The chip thickness and the tool wear are observed under Tool Maker's Microscope. Natural image of serrated chip formation of Titanium alloy is measured based on the pitch, Valley, average peak and length of the chip. Table 2 shows the experimental details for the machining of Titanium alloy (Ti-6Al-4V). Fig. 1 shows the experimental set-up. 
Table 2. Machining Conditions of Titanium alloy (Ti-6Al-4V)

\begin{tabular}{|l|l|}
\hline Work Material & Titanium alloy (Ti-6Al-4V) \\
\hline Dimensions of workpiece & $10 *^{*} 25$ (Length * Diameter) $(\mathrm{mm})$ \\
\hline Tool Material and specification & Polycrystalline Diamond, DNMG110408 \\
\hline Rake angel of tool & $-5^{\circ}$ \\
\hline Clearance angel & $+5^{\circ}$ \\
\hline Cutting conditions & Dry and MQL \\
\hline Cutting speed & $100,125,150,175$ and $200(\mathrm{~m} / \mathrm{min})$ \\
\hline Feed rate & $0.15(\mathrm{~mm} / \mathrm{rev})$ \\
\hline Depth of cut & $0.5(\mathrm{~mm})$ \\
\hline
\end{tabular}

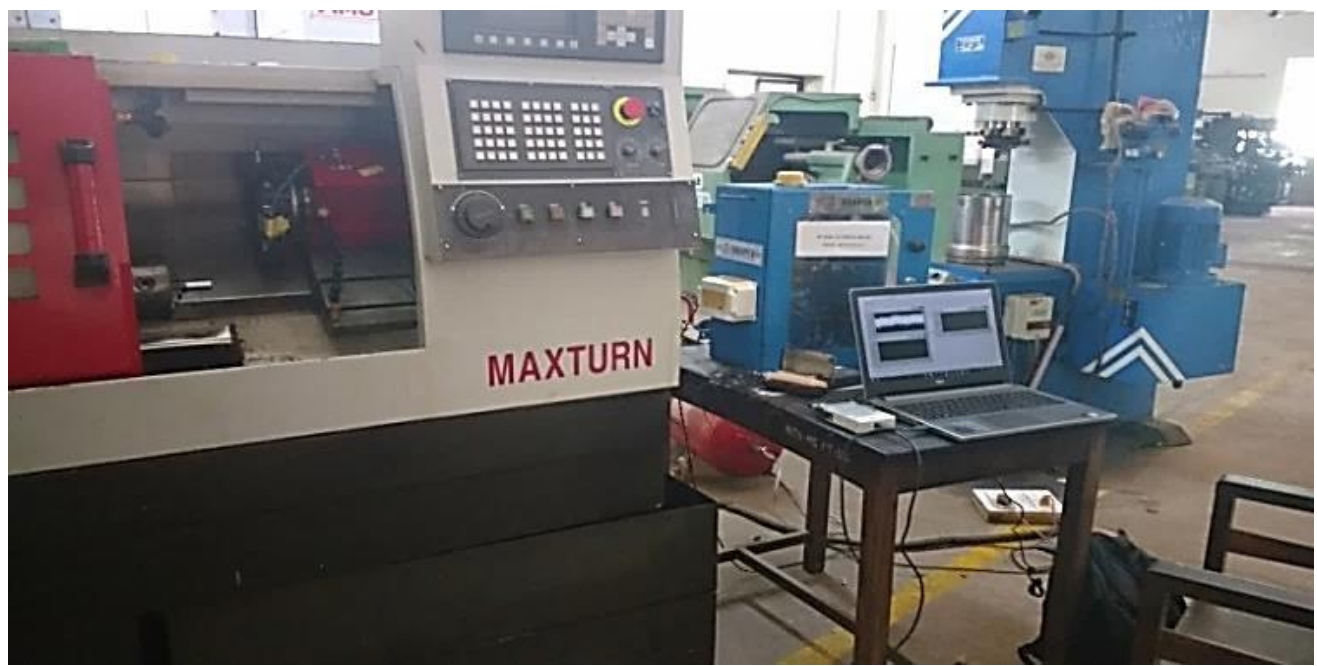

Fig. 1. Experimental setup

\subsection{Micro-holes on Polycrystalline Diamond Insert}

Polycrystalline Diamond (PCD) is used as a cutting tool in this research work. Micro holes are made on the rake face and flank face of the cutting tool insert, very close to chip-tool contact area to effect the heat reduction through the micro-pool lubrication along the cutting edge. In designing the holes pattern, circular holes are selected because this shape is easy to be drilled using drill bits. Two different types of designs are modeled and simulated to select the best designs for further experimentation. The holes diameters are varied from $0.4 \mathrm{~mm}$ to $0.8 \mathrm{~mm}$ and the depth of the hole from $1 \mathrm{~mm}$ to $3 \mathrm{~mm}$ respectively with the equidistance of $1 \mathrm{~mm}$ and $2 \mathrm{~mm}$. Table 3 shows the different designs with varied depth and diameter of the holes. The main goal is to drill deep holes so that they retain more lubricants to reduce the temperature. Fig. 2(a) and 2(b) shows the two designs of the Microhole pattern on the rake and flank face of the PCD insert. 
Table 3. Different designs with varied depth and diameter of the holes

\begin{tabular}{|c|c|}
\hline Design Pattern & Dimensions \\
\hline Design 1 & $0.4 \mathrm{~mm}$ Dia. and $1 \mathrm{~mm}$ equidistance \\
\hline Design 2 & $0.6 \mathrm{~mm}$ Dia. and $1 \mathrm{~mm}$ equidistance \\
\hline Design 3 & $0.6 \mathrm{~mm}$ Dia. and $2 \mathrm{~mm}$ equidistance \\
\hline Design 4 & $0.4 \mathrm{~mm}$ Dia. and $2 \mathrm{~mm}$ equidistance \\
\hline Design 5 & $0.4 \mathrm{~mm}$ Dia. $0.6 \mathrm{~mm}$ Through Hole, $2 \mathrm{~mm}$ equidistance \\
\hline Design 6 & $0.6 \mathrm{~mm}$ Dia. $0.6 \mathrm{~mm}$ Through Hole, $2 \mathrm{~mm}$ equidistance \\
\hline Design 7 & $0.6 \mathrm{~mm}$ Dia. $0.8 \mathrm{~mm}$ Through Hole, $2 \mathrm{~mm}$ equidistance \\
\hline
\end{tabular}
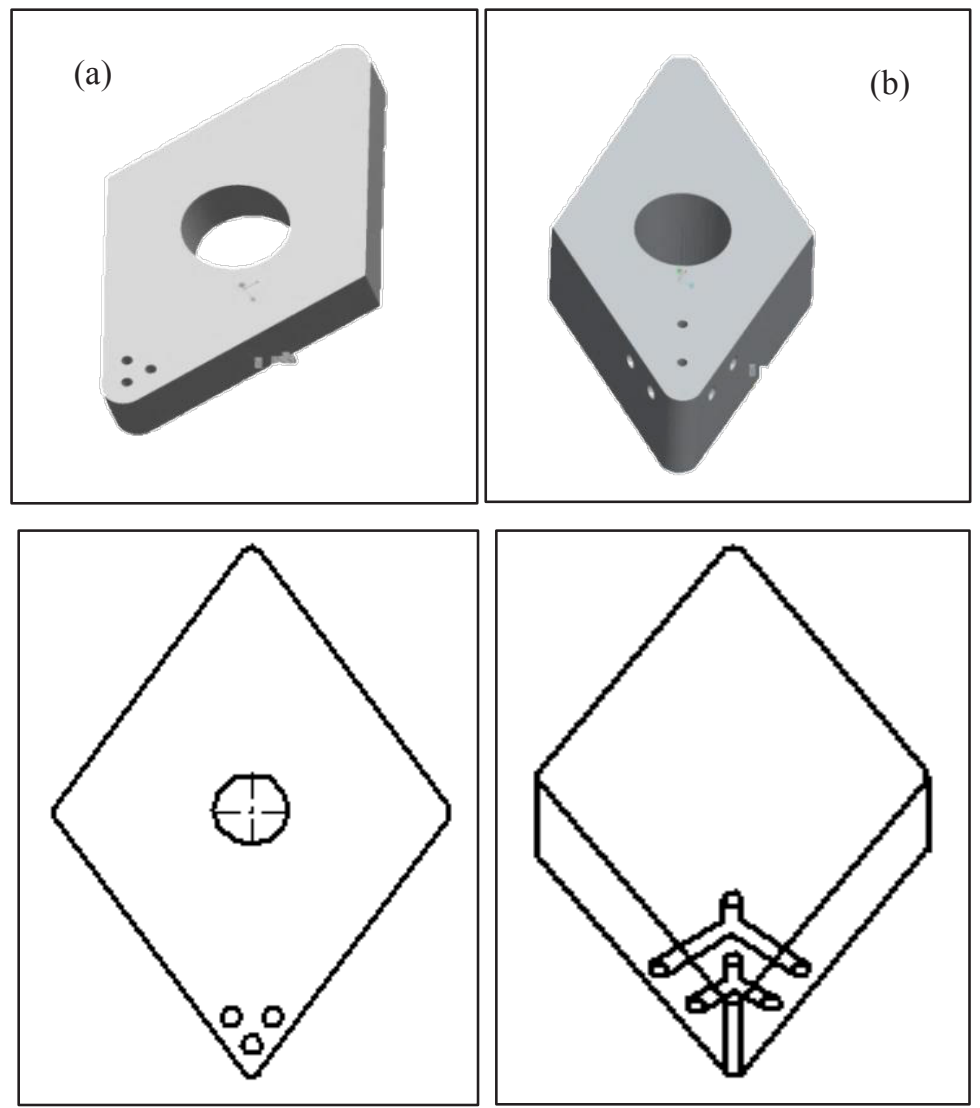

Fig. 2. CAD model of different type of perforation designs on rake and flank face of PCD insert

\section{FE Modeling and Simulation}

To estimate the effect of micro-holes on the mechanical strength of the cutting tool when in use [3], Finite Element modeling is performed using DEFORM-3D ${ }^{\mathrm{TM}} 10.2$ contingents upon an updated Lagrangian formulation. This contemplates the mesh to be involved with a workpiece during the machining and as a resulting chip is formed which is a function of deformation process for which the cutting conditions and material constants need not be preset. The workpiece material is fully constrained and the tool material movement is allowed in the Y-axis [10]. The thermo-mechanical and physical properties of the workpiece and tool materials of Titanium alloy (Ti-6Al-4V) and PCD were calculated from 
material properties and are merged into the FEM model. The workpiece is modeled as a plastic material and the tool insert as a rigid material. Fourteen thousand tetrahedral elements were taken for the workpiece material. PRO-E Creo 5 software is used to model the micro-holes on cutting tools that are drilled along the preferred orientations on insert DNMG1 10408 tool geometry and micro-hole pattern as shown in Table 3 are considered.

3D tool model with micro-holes in different orientations and related tool material properties are imported into the DEFORM-3D ${ }^{\mathrm{TM}}$ software package during the formulation of machining simulation. The cutting tool is defined by 16,000 elements and was remeshed with 1,40,000 elements for the superior scattering of the output parameters like cutting force, Stress distribution, Strain distribution and temperature distribution.

The 3D FEM simulation deformation process is carried out with varying cutting speed and constant feed rate and depth of cut. The simulation is performed with the micro-hole textured tool and the normal insert. The results after completion of simulation such as cutting force, stress distribution, strain distribution and temperature distribution are validated with experimental results. Fig. 3 shows the different FE model for different design pattern. 

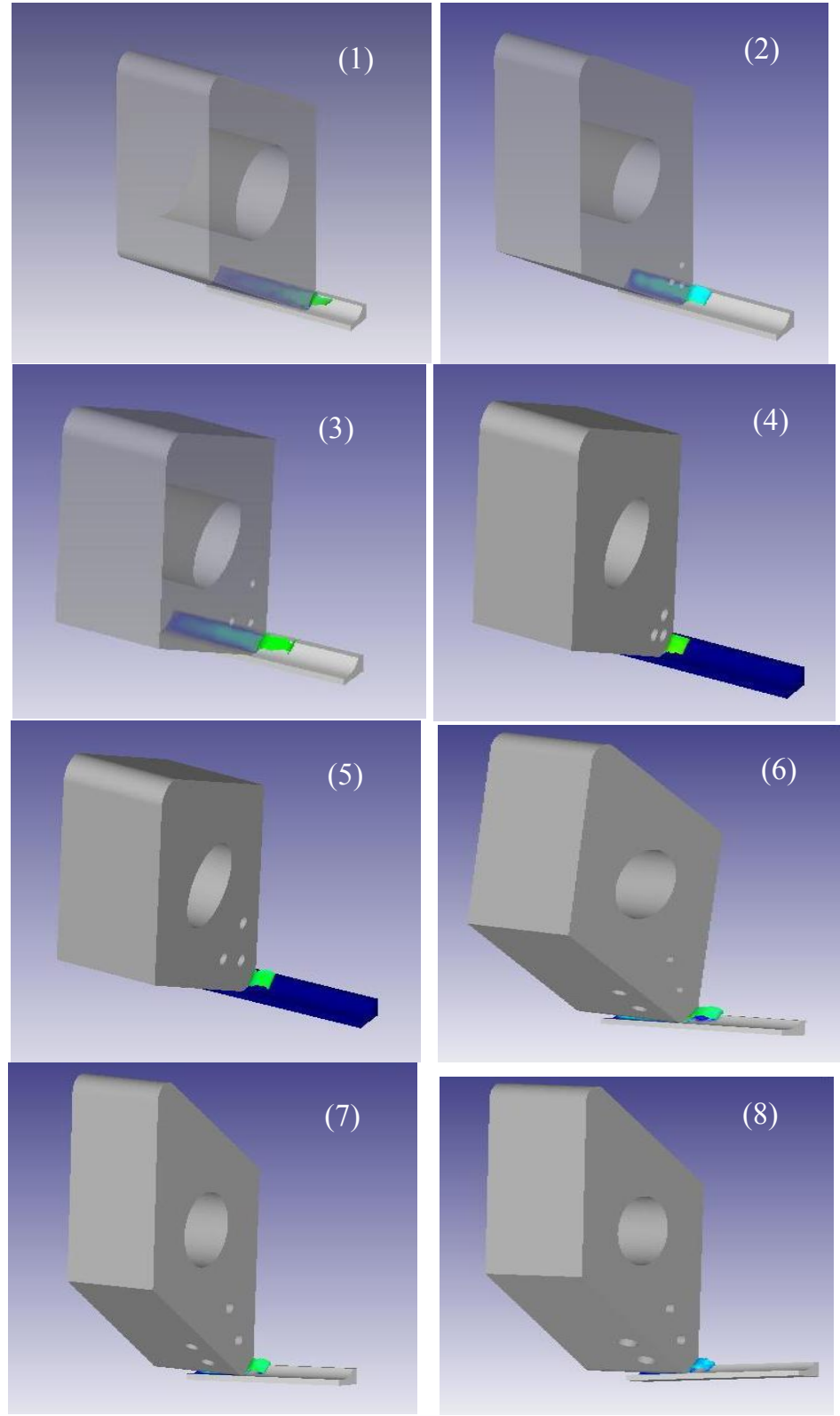

Fig. 3. FE model (1) Normal Insert (2) $0.4 \mathrm{~mm}$ Dia. and $1 \mathrm{~mm}$ equidistance (3) $0.4 \mathrm{~mm}$ Dia. and $2 \mathrm{~mm}$ equidistance (4) $0.6 \mathrm{~mm}$ Dia. and $1 \mathrm{~mm}$ equidistance (5) $0.6 \mathrm{~mm}$ Dia. and $2 \mathrm{~mm}$ equidistance (6) $0.4 \mathrm{~mm}$ Dia. $0.6 \mathrm{~mm}$ Through Hole, $2 \mathrm{~mm}$ equidistance (7) $0.6 \mathrm{~mm}$ Dia. $0.6 \mathrm{~mm}$ Through Hole, $2 \mathrm{~mm}$ equidistance (8) $0.6 \mathrm{~mm}$ Dia. $0.8 \mathrm{~mm}$ Through Hole, $2 \mathrm{~mm}$ equidistance

\subsection{Friction Modeling}

DEFORM-3D ${ }^{\text {TM }} 10.2$ software uses a coefficient of friction as defined by the Coulomb friction in the following Eq. (2) for FEM code to model the frictional demeanor of Titanium alloy (Ti-6Al-4V) deformation. This friction law is used from the time when it has been 
verified that friction coefficient is more important in friction modeling than the law which is based.

As far as force is concerned the good predictive value for the frictional coefficient ranges from $0.8-0.9$ [16].

$$
\tau=\mu \sigma_{\mathrm{n}}
$$

$\tau=$ shear stress

$\mu=$ friction coefficient

$\sigma_{\mathrm{n}}=$ normal stress

Shear stress is the product of Coulomb friction coefficient and the normal stress

\section{Results and Discussions}

The results of Finite Element Analysis for cutting force, temperature distribution, strain, and stress, with the material model input for different designs, are shown here. The analysis is performed with varying cutting velocities ranging from $100 \mathrm{~m} / \mathrm{min}$ to $200 \mathrm{~m} / \mathrm{min}$ and constant feed and depth of cut [17]. The Finite Element output is measured around at near stable state circumstances to ensure the comparisons with normal insert.

\subsection{FEM based Prediction of Cutting Force}

Fig. 4 plots the predictions of cutting force by FEM Simulation model comparing with the results of normal insert and the designed insert. The predicted cutting force increased with the cutting velocity ranging from $100 \mathrm{~m} / \mathrm{min}$ to $125 \mathrm{~m} / \mathrm{min}$ and showed the marginal decrease and increase from $125 \mathrm{~m} / \mathrm{min}$ to $175 \mathrm{~m} / \mathrm{min}$ and thereafter steadily decreased for cutting velocity between $175 \mathrm{~m} / \mathrm{min}$ to $200 \mathrm{~m} / \mathrm{min}$. The increase in the cutting force is as a result of the strain hardening effect which modifies the inclination slightly and then decreases between $175 \mathrm{~m} / \mathrm{min}$ to $200 \mathrm{~m} / \mathrm{min}$ is owing to increase in cutting temperature resulting in the thermal tempering of the workpiece in the normal insert. The predicted values of cutting force are shown in Table 5.

Finally, there is a flawless decrease in cutting force between the normal insert and the micro-hole textured inserts. Compared to that normal insert, a reduction in cutting force by $14 \%$ to $22 \%$ is noticed when machining steel [18] with micro-hole textured insert as shown in Table 4. The cutting forces are also impacted by the coefficient of friction and also the law of friction. The higher the friction values, the cutting force also increases. In this research work, the JC-model is employed with $\mu=0.3$ Coulomb friction constant in friction modeling [16]. Several simulations were performed with the same circumstances to study the repeatability of the results since the experimentation is costlier. All the simulations showed similar results. 


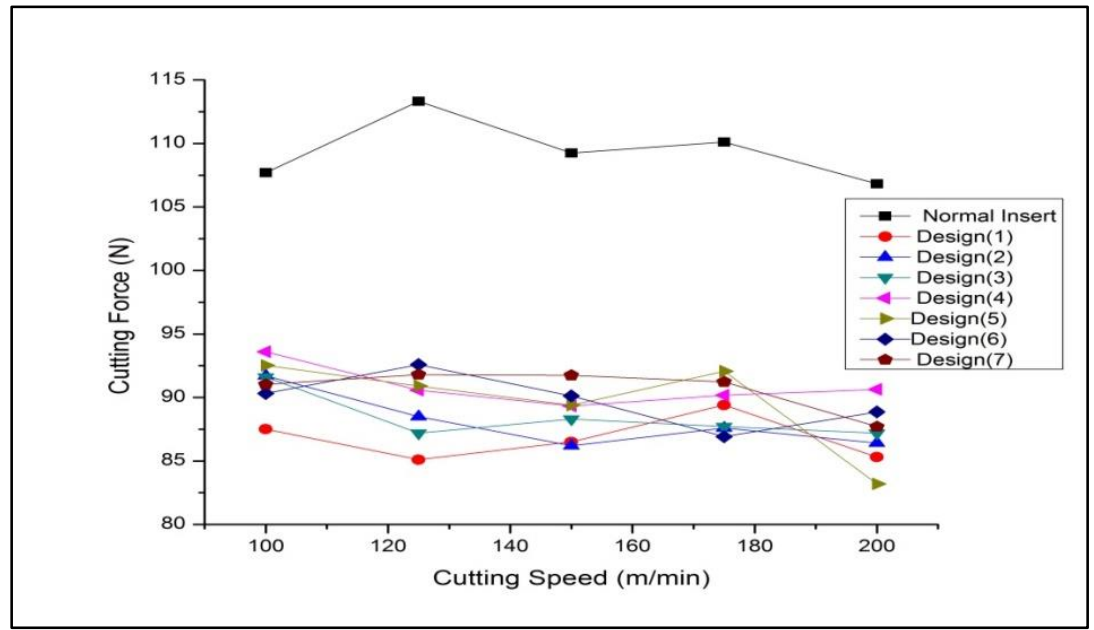

Fig. 4. Comparison of cutting force with normal and designed inserts

Table 4. Error or Percentage decrease in Cutting force for FEM simulated Model

\begin{tabular}{|c|c|c|c|c|c|}
\hline \multicolumn{7}{|c|}{ Comparison of Cutting Force with Error \% } \\
\hline & $100 \mathrm{~m} / \mathrm{min}$ & $125 \mathrm{~m} / \mathrm{min}$ & $150 \mathrm{~m} / \mathrm{min}$ & $175 \mathrm{~m} / \mathrm{min}$ & $200 \mathrm{~m} / \mathrm{min}$ \\
\hline Normal Insert & 107.71 & 113.32 & 109.26 & 110.12 & 106.83 \\
\hline Design 1 & 87.50 & 85.10 & 86.5 & 89.4 & 85.3 \\
(Error \%) & $(-18.76)$ & $(-24.90)$ & $(-20.83)$ & $(-18.81)$ & $(-20.15)$ \\
\hline Design 2 & 91.7 & 88.5 & 86.2 & 87.6 & 86.4 \\
$($ Error \%) & $(-14.86)$ & $(-21.90)$ & $(-21.10)$ & $(-20.45)$ & $(-19.12)$ \\
\hline Design 3 & 91.6 & 87.2 & 88.31 & 87.7 & 87.2 \\
(Error \%) & $(-14.95)$ & $(-23.04)$ & $(-19.17)$ & $(-20.35)$ & $(-18.37)$ \\
\hline Design 4 & 93.6 & 90.57 & 89.34 & 90.18 & 90.64 \\
(Error \%) & $(-13.09)$ & $(-20.07)$ & $(-18.23)$ & $(-18.10)$ & $(-15.15)$ \\
\hline Design 5 & 92.52 & 90.91 & 89.39 & 92.07 & 83.19 \\
(Error \%) & $(-14.10)$ & $(-19.77)$ & $(-18.18)$ & $(-16.39)$ & $(-22.12)$ \\
\hline Design 6 & 90.32 & 92.59 & 90.12 & 86.92 & 88.86 \\
(Error \%) & $(-16.14)$ & $(-18.29)$ & $(-17.51)$ & $(-21.06)$ & $(-16.82)$ \\
\hline Design 7 & 91.04 & 91.80 & 91.75 & 91.23 & 87.70 \\
(Error \%) & $(-15.47)$ & $(-18.99)$ & $(-16.02)$ & $(-17.15)$ & $(-17.90)$ \\
\hline
\end{tabular}

\subsection{FEM based Prediction of Effective Stress}

Fig. 5 predicts the effective stress variations in FE models of the normal insert and different designed patterns of inserts. The effective stress plot for all design patterns reveals that maximum stresses are usually found in the primary deformation region where there is a contact between tool and workpiece. The stress distribution at the deformed surface is residual in nature and decreases at the uncut surface and at chip deformed surface. The seven designs prove good stability in modeling, proposing that JC law is noble when evaluating overall output stress.

All seven designs predict the similar ranges (1738-1860 MPa) for effective stress, proposing that material constants of the model combine to produce the similar stress pattern in the course of machining when compared with the normal insert as shown in Table 5. The stress concentrations are less near the segments in the designed pattern at their deformation 
zones. The normal insert shows irregular stress distribution at primary and secondary zones when compared. It should be acclaimed that there is no specific stress concentration due to the perforations on the rake face and flank face of the insert.

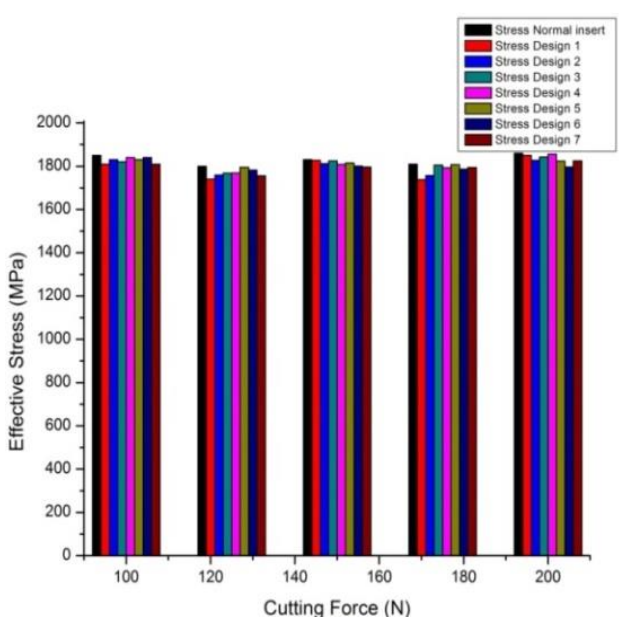

Fig. 5. Predicted Stress distribution graph of Normal Insert and Designed Inserts

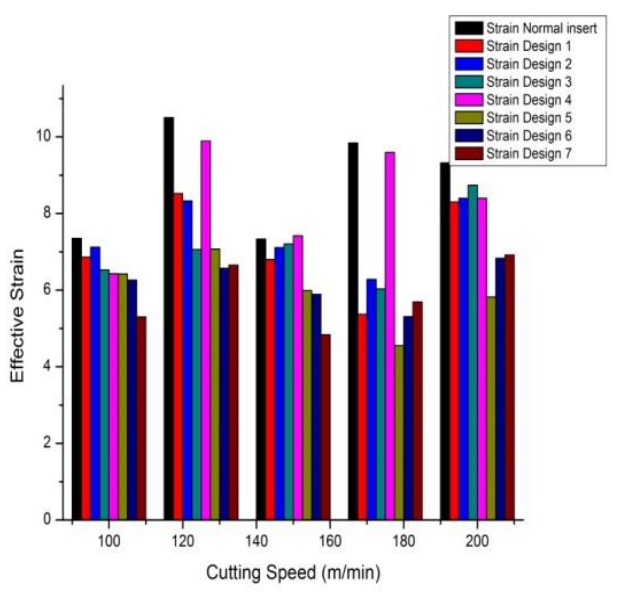

Fig. 6. Predicted Strain distribution graph of Normal Insert and Designed Inserts

\subsection{FEM based Prediction of effective Strain}

Fig. 6 shows the effective strain variation of predicted values with FE models of the normal insert and different designed patterns of inserts. The strain distribution in the plastic region is greater at the primary deformation region followed by secondary region and very less at the end of the chip. The formation of chip in titanium alloy suggests a convoluted formation mode resulting in segments and serrations even at lower cutting speeds. In other material, this type of formation occurs only during high-speed cutting. The simulated chip formation for different designs shows similar strain patterns. The strain distribution is less in designed inserts when compared with the normal insert, as the values of which are shown in Table 5. Minor variations can be observed in the secondary and primary deformation zones.

\subsection{FEM based Prediction of Temperature}

Fig. 7 shows the temperature predictions with FE models for normal insert and different designed patterns of inserts. The heat transfer takes place in the primary region where the deformation occurs. The plastic work material is converted to heat in shear zone and frictional heat is generated at the chip-tool interface. The Titanium alloy has the low thermal conductivity property which ensures less heat dissipation which leads to rapid tool wear of cutting tool insert which reduces the tool life. Hence, lubrication is necessary with cutting fluids or the cryogenic coolants for the removal of heat generation. In this FEM simulation model, the workpiece is evaluated as plastic and the cutting tool as rigid material to understand the heat transfer during the deformation of titanium alloy in the machining process. The experimental temperature will usually be more near chip-tool interface followed by shear plane and least at the uncut surface. 
Table 5 shows the predicted temperature distributions of machining Titanium alloy. The difference in temperature is less for micro-holed textured inserts when compared with normal inserts. This can prove that micro-hole textured pattern helps in the decrease of tool wear which finally increases tool life. The minimum value can be attributed to the discrepancy in the value of ' $\mathrm{m}$ ', the thermal softening coefficient in the model. The cutting speed can also affect the temperature distribution. Generally, the temperature distribution may be less than normal value on account of a small cutting process in the simulation.

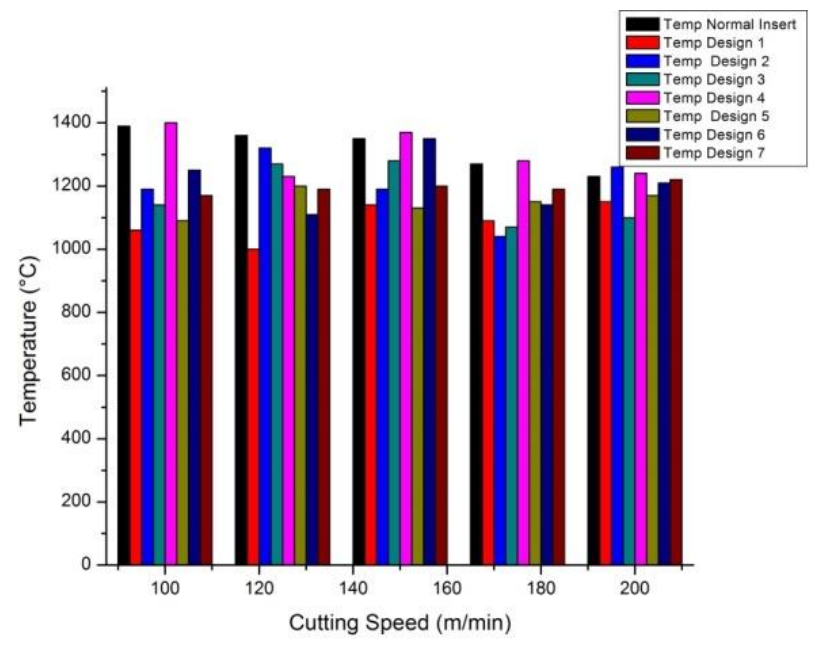

Fig. 7. Predicted Temperature distribution graph of Normal insert and Designed inserts. 
Table 5. Simulation values of Cutting Force, Stress, Strain and Temperature distributions for Normal insert and designed insert

\begin{tabular}{|c|c|c|c|c|c|c|c|c|c|}
\hline $\begin{array}{l}\text { Cutting } \\
\text { Speed } \\
(\mathrm{m} / \mathrm{min})\end{array}$ & $\begin{array}{c}\text { Simulation } \\
\text { Output } \\
\text { parameters }\end{array}$ & $\begin{array}{l}\text { Normal } \\
\text { Insert }\end{array}$ & $\begin{array}{c}\text { Design } \\
\text { Insert } \\
1\end{array}$ & $\begin{array}{c}\text { Design } \\
\text { Insert } \\
2\end{array}$ & $\begin{array}{c}\text { Design } \\
\text { Insert } \\
3\end{array}$ & $\begin{array}{c}\text { Design } \\
\text { Insert } \\
4\end{array}$ & $\begin{array}{c}\text { Design } \\
\text { Insert } \\
5\end{array}$ & $\begin{array}{c}\text { Design } \\
\text { Insert } \\
6\end{array}$ & $\begin{array}{c}\text { Design } \\
\text { Insert } \\
7\end{array}$ \\
\hline \multirow{4}{*}{100} & $\begin{array}{c}\text { Cutting } \\
\text { Force }(\mathrm{N})\end{array}$ & 107.71 & 87.50 & 91.70 & 91.6 & 93.60 & 92.52 & 90.32 & 91.04 \\
\hline & $\begin{array}{l}\text { Stress } \\
(\mathrm{MPa})\end{array}$ & 1850 & 1810 & 1830 & 1820 & 1840 & 1830 & 1840 & 1810 \\
\hline & Strain & 7.35 & 6.86 & 7.12 & 6.53 & 6.43 & 6.42 & 6.26 & 5.30 \\
\hline & $\begin{array}{c}\text { Temperature } \\
\left({ }^{\circ} \mathrm{C}\right)\end{array}$ & 1230 & 1060 & 1190 & 1140 & 1400 & 1090 & 1250 & 1170 \\
\hline \multirow{4}{*}{125} & $\begin{array}{c}\text { Cutting } \\
\text { Force }(\mathrm{N})\end{array}$ & 113.32 & 85.10 & 88.50 & 87.20 & 9.57 & 90.91 & 92.59 & 91.80 \\
\hline & $\begin{array}{l}\text { Stress } \\
(\mathrm{MPa})\end{array}$ & 1800 & 1740 & 1759 & 1768 & 1769 & 1795 & 1782 & 1756 \\
\hline & Strain & 10.5 & 8.52 & 8.33 & 7.06 & 9.89 & 7.07 & 6.57 & 6.65 \\
\hline & $\begin{array}{c}\text { Temperature } \\
\left({ }^{\circ} \mathrm{C}\right)\end{array}$ & 1360 & 1000 & 1320 & 1270 & 1230 & 1200 & 1110 & 1190 \\
\hline \multirow{4}{*}{150} & $\begin{array}{c}\text { Cutting } \\
\text { Force }(\mathrm{N})\end{array}$ & 109.26 & 86.50 & 86.20 & 88.31 & 89.34 & 89.39 & 90.12 & 91.75 \\
\hline & $\begin{array}{l}\text { Stress } \\
(\mathrm{MPa})\end{array}$ & 1830 & 1827 & 1812 & 1825 & 1808 & 1815 & 1801 & 1796 \\
\hline & Strain & 7.33 & 6.80 & 7.11 & 7.20 & 7.42 & 5.99 & 5.89 & 4.84 \\
\hline & $\begin{array}{c}\text { Temperature } \\
\left({ }^{\circ} \mathrm{C}\right)\end{array}$ & 1350 & 1140 & 1190 & 1280 & 1370 & 1130 & 1350 & 1200 \\
\hline \multirow{4}{*}{175} & $\begin{array}{c}\text { Cutting } \\
\text { Force }(\mathrm{N})\end{array}$ & 110.12 & 89.40 & 87.60 & 87.70 & 90.18 & 92.07 & 86.92 & 91.23 \\
\hline & $\begin{array}{l}\text { Stress } \\
(\mathrm{MPa})\end{array}$ & 1810 & 1738 & 1757 & 1805 & 1793 & 1807 & 1786 & 1794 \\
\hline & Strain & 9.84 & 5.37 & 6.28 & 6.03 & 9.59 & 4.55 & 5.31 & 5.69 \\
\hline & $\begin{array}{c}\text { Temperature } \\
\left({ }^{\circ} \mathrm{C}\right)\end{array}$ & 1270 & 1090 & 1040 & 1070 & 1280 & 1150 & 1140 & 1190 \\
\hline \multirow{4}{*}{200} & $\begin{array}{c}\text { Cutting } \\
\text { Force }(\mathrm{N})\end{array}$ & 106.83 & 85.3 & 86.40 & 87.20 & 90.64 & 83.19 & 88.86 & 87.70 \\
\hline & $\begin{array}{l}\text { Stress } \\
(\mathrm{MPa}) \\
\end{array}$ & 1860 & 1850 & 1827 & 1842 & 1856 & 1824 & 1796 & 1825 \\
\hline & Strain & 9.32 & 8.30 & 8.40 & 8.74 & 8.40 & 5.82 & 6.83 & 6.92 \\
\hline & $\begin{array}{c}\text { Temperature } \\
\left({ }^{\circ} \mathrm{C}\right)\end{array}$ & 1390 & 1150 & 1260 & 1100 & 1240 & 1170 & 1210 & 1220 \\
\hline
\end{tabular}

\section{Conclusions}

The research work aims at scrutinizing the effect of different micro-hole textured PCD inserts of material constitutive model parameters of the Johnson-Cook model in foreseeing the cutting force, effective stress, strain, and temperature distribution in deformation of Titanium alloy (Ti-6Al-4V). The material models flow stress data is assigned to FEM code and the model is built to show the replica of machining process of Titanium alloy (Ti-6Al-4V). The cutting force, effective strain, stress, and temperature were investigated 
for all the seven different micro-textured inserts and compared with the normal insert. The following conclusions are drawn:

1. The micro-hole textured insert is very efficient in dropping cutting force, consequently cutting energy and chip-tool contact length compared with normal insert.

2. Design 2, 4, 6 and 7 showed the better enactment in terms of Cutting Force, Stress, Strain and Temperature distribution when compared with other designs. Out of simulation results obtained for other designs it was deduced to that, the designs 2,4, 6 and 7 give better results

3. All the designs predicted the global phenomena of stress, strain, and temperature with worthy correspondence to each other. This shows that JC constitutive equation is robust in modeling the deformation behavior from the global point of view.

4. The FE model assumption of material properties is found to be appropriate to model the machining of titanium alloy and appraises the pros and cons employed in the model parameter.

\section{References}

1. E. O. Ezugwu, J. Bonney, \& Y. Yamane, An overview of the machinability of aeroengine alloys, Journal of materials processing technology, 134(2), 233-253, (2003).

2. L. E. Sanchez, D. A. Palma, G. L. Marinescu, I. Modolo, D. L. Nalon, L. J. \& A. E. Santos, Effect of different methods of cutting fluid application on turning of a difficult-to-machine steel (SAE EV-8), Proceedings of the Institution of Mechanical Engineers, Part B: Journal of Engineering Manufacture, 227(2), 220-234, (2013).

3. Shuting. Lei, S. Devarajan, \& Z. Chang, A study of micropool lubricated cutting tool in machining of mild steel, Journal of materials processing technology, 209(3), 16121620, (2009).

4. N. Kawasegi, H. Sugimori, H. Morimoto, N. Morita, \& I. Hori, Development of cutting tools with microscale and nanoscale textures to improve frictional behavior, Precision Engineering, 33(3), 248-254, (2009).

5. D. Jianxin, W. Ze, L. Yunsong, Q. Ting, \& C. Jie, Performance of carbide tools with textured rake-face filled with solid lubricants in dry cutting processes, International Journal of Refractory Metals and Hard Materials, 30(1), 164-172, (2012).

6. T. Sugihara, \& T. Enomoto, Development of a cutting tool with a nano/micro-textured surface-Improvement of anti-adhesive effect by considering the texture patterns, Precision Engineering, 33(4), 425-429, (2009).

7. P. Koshy, \& J. Tovey, Performance of electrical discharge textured cutting tools, CIRP Annals-Manufacturing Technology, 60(1), 153-156, (2011).

8. C. Ma, \& H. Zhu, An optimum design model for textured surface with elliptical-shape dimples under hydrodynamic lubrication, Tribology International, 44(9), 987-995, (2011).

9. W. M. Da Silva, M. P. Suarez, A. R. Machado, \& H. L. Costa, Effect of laser surface modification on the micro-abrasive wear resistance of coated cemented carbide tools, Wear, 302(1), 1230-1240, (2011).

10. K. S. Vijay Sekar, \& M. Pradeep Kumar, Finite element simulations of Ti6A14V titanium alloy machining to assess material model parameters of the Johnson-Cook 
constitutive equation, Journal of the Brazilian Society of Mechanical Sciences and Engineering, 33(2), 203-211, (2011).

11. Donald. Lesuer, Experimental investigation of material models for Ti-6Al-4V and 2024-T3, Livermore: University of California, Lawrence Livermore National Laboratory, 1-36, (1999).

12. M. Calamaz, D. Coupard, \& F. Girot, A new material model for $2 \mathrm{D}$ numerical simulation of serrated chip formation when machining titanium alloy Ti-6Al4V, International Journal of Machine Tools and Manufacture, 48(3), 275-288, (2008).

13. K. Satyanarayana, A. V. Gopal, \& P. B. Babu, Finite Element Simulation of Cutting Forces in Turning Ti6Al4V Using DEFORM 3D, In ASME 2013 International Mechanical Engineering Congress and Exposition, American Society of Mechanical Engineers, volume 2A, V02AT02A083, (2013).

14. S. Thamizhmanii, R. Ahmad, \& S. Hasan, Performance of CBN and PCBN Tools on the Machining of Hard AISI 440C Martensitic Stainless Steel. In Advanced Materials Research, 264, 1137-1147, (2011).

15. M. Fahad, P. T. Mativenga, \& M. A. Sheikh, A comparative study of multilayer and functionally graded coated tools in high-speed machining, The International Journal of Advanced Manufacturing Technology, 62(1-4), 43-57, (2011).

16. L. Filice, F. Micari, S. Rizzuti, \& D. Umbrello, A critical analysis on the friction modelling in orthogonal machining, International Journal of Machine Tools and Manufacture, 47(3), 709-714, (2011).

17. B. Ozcelik, E. Kuram, \& B. T. Simsek, Comparison of dry and wet end milling of AISI 316 stainless steel, Materials and Manufacturing Processes, 26(8), 1041-1049, (2011).

18. D. Arulkirubakaran, V. Senthilkumar, \& V. Kumawat, Effect of micro-textured tools on machining of Ti-6Al-4V alloy: an experimental and numerical approach, International Journal of Refractory Metals and Hard Materials, 54, 165177, (2016). 